\title{
Prospective evaluation of yield of endoscopic ultrasonography in the etiological diagnosis of "idiopathic" acute pancreatitis
}

\author{
Narendra S. Choudhary, Rinkesh Kumar Bansal, Vinit Shah, Mukesh Nasa, Rajesh Puri, \\ Ragesh Thandassery, Rajiv Ranjan Singh, Amit Bhasin, Sumit Bhatia, S. R. Misra, Suraj Bhagat, \\ Chitranshu Vashishtha, Randhir Sud
}

Institute of Digestive and Hepatobiliary Sciences, Medanta - The Medicity, Gurgaon, Haryana, India

\begin{abstract}
Background: Etiology of acute pancreatitis (AP) remains idiopathic in $30 \%$ of patients. Endoscopic ultrasound (EUS) has been shown to increase the diagnostic yield in patients with idiopathic AP (IAP). Aim: The aim of this study was to evaluate the role of EUS in achieving etiological diagnosis in patients with IAP. Materials and Methods: Consecutive 192 patients with IAP were evaluated prospectively with EUS over a period of 2 years. Patients who had no etiological diagnosis for AP after detailed history, clinical examination, laboratory investigations, and magnetic resonance cholangiopancreatography were included in the study. Results: The mean age of patients was $34.6 \pm 12$ and male:female ratio was $2.1: 1$. Of these, 135 patients had gallbladder intact (Group A) and 57 patients had undergone cholecystectomy (Group B). In Group A, EUS identified a possible cause in 79 (58.5\%) patients; microlithiasis $(n=48)$, chronic pancreatitis (CP) $(n=23)$, common bile duct $(\mathrm{CBD})$ and gallbladder stone $(n=3)$, pancreatic divisum $(n=3)$, small pancreatic tumor $(n=1)$, and anomalous pancreaticobiliary junction $(n=1)$. In Group B, EUS yielded diagnosis in $28(49.1 \%)$ patients; CP $(n=22)$, ascariasis $(n=3)$, CBD stone $(n=2)$, and pancreatic divisum $(n=1)$. Overall EUS helped in achieving etiological diagnosis in 107 (55.1\%) of patients with IAP. The presence of intact gallbladder showed a tendency for increased diagnostic yield $(P=0.06)$. Conclusion: EUS is a useful modality to establish the diagnosis in IAP and this technique should be incorporated in the evaluation of IAP.

Key words Endoscopic ultrasound, idiopathic acute pancreatitis, microlithiasis
\end{abstract}

\section{Introduction}

Common causes of acute pancreatitis (AP) include biliary stones, alcohol, hypercalcemia, hypertriglyceridemia, drugs, and trauma. The etiology of AP remains undetected in

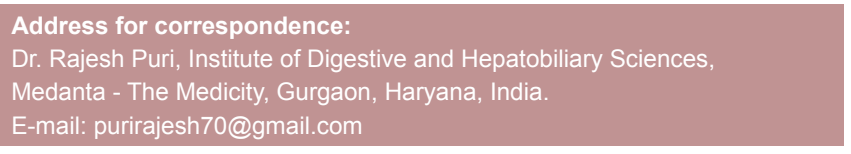

\begin{tabular}{|l|c|}
\hline \multicolumn{2}{|c|}{ Access this article online } \\
\hline \multirow{2}{*}{$\begin{array}{l}\text { Website: } \\
\text { www.jdeonline.in }\end{array}$} & Quick Response Code \\
\hline DOI: & \\
10.4103/0976-5042.195725 & \\
\hline
\end{tabular}

$10 \%-30 \%$ of patients after history, laboratory, and noninvasive imaging studies. ${ }^{[1]}$ Etiological evaluation is critical to optimize the treatment strategy and to prevent recurrence that may occur in $10 \%-30 \%$ of patients and has a risk of mortality. ${ }^{[2,3]}$ Endoscopic ultrasound (EUS) has emerged as an important procedure to identify the etiology of idiopathic AP (IAP). ${ }^{[4-9]}$ Microlithiasis is a major cause of an unexplained attack of AP in patients with gallbladder in situ, whereas chronic

This is an open access article distributed under the terms of the Creative Commons Attribution-NonCommercial-ShareAlike 3.0 License, which allows others to remix, tweak, and build upon the work non-commercially, as long as the author is credited and the new creations are licensed under the identical terms.

For reprints contact: reprints@medknow.com

How to cite this article: Choudhary NS, Bansal RK, Shah V, Nasa M, Puri R, Thandassery R, et al. Prospective evaluation of yield of endoscopic ultrasonography in the etiological diagnosis of "idiopathic" acute pancreatitis. J Dig Endosc 2016;7:133-6. 
pancreatitis $(\mathrm{CP})$ is common in those with recurrent attacks who have previously undergone cholecystectomy. ${ }^{[10]}$ Microscopic examination of bile, ${ }^{[10,11]}$ endoscopic retrograde cholangiopancreatography (ERCP),${ }^{[11,12]}$ and magnetic resonance cholangiopancreatography $(\mathrm{MRCP})^{[13]}$ have been used to find etiology in these cases; however, ERCP has some chances of complications and MRCP is inferior to EUS in detecting $<5 \mathrm{~mm}$ stones. ${ }^{[14,15]}$ EUS offers several advantages over these modalities; it provides better resolution to diagnose small stones/tumors ${ }^{[1]}$ and $\mathrm{CP}{ }^{[16]}$ Most of the studies reported from India regarding acute idiopathic pancreatitis were before routine use of EUS. We evaluated the role of EUS for etiological diagnosis in a large group of patients with AIP.

\section{Materials and Methods}

The study was conducted over a period of 2 years at a Tertiary Care Centre in North India. Informed consent was taken from all the patients and study had the Institute's Ethical Committee approval. The study included 192 patients above 12 years of age, with one or more documented attacks of unexplained AP. AP was defined by the presence of characteristic abdominal pain and raised serum amylase or lipase levels to $\geq 3$ times the upper limit of normal or imaging features suggestive of AP. The episode(s) of AP were considered as idiopathic when no cause could be identified after biochemical investigations and imaging. Patients with AP within the past 6 weeks, history of significant alcohol intake, deranged calcium or triglyceride levels, diagnosed biliary stone disease, CP, pancreas divisum were excluded.

\section{Methods}

Before EUS study, the following information was collected: age, sex smoking, alcohol consumption, number of previous episodes of AP, and the time interval from the last attack. History of abdominal trauma, infection, and relevant drug intake were also collected. Investigations including lipid profile, fasting blood sugar, liver function tests, autoimmune markers, and calcium levels were done before inclusion. All patients had a transabdominal ultrasound and either or both of a helical computed tomography (CT) scan and magnetic resonance imaging done before the EUS study.

\section{Endoscopic ultrasound protocol}

Informed consent was obtained from all the patients before the study. The study was approved by the Institutional Review Board of our hospital, and ICMR guidelines for conducting a study were followed. The instruments used were echoendoscopes (FG 34 UX; Pentax, Japan, and GF-UCT140 AL5; Olympus, Japan) with a longitudinal convex ultrasound transducer with an adjustable ultrasonic frequency of $5,7.5$, or $10 \mathrm{MHz}$, in combination with an Ultrasound Scanner (EUB 6500; Hitachi, Tokyo, Japan).

\section{Study definitions}

Both parenchymal and ductal features were recorded, and CP was defined as per Rosemont consensus [Figure 1]. ${ }^{[17]}$ EUS

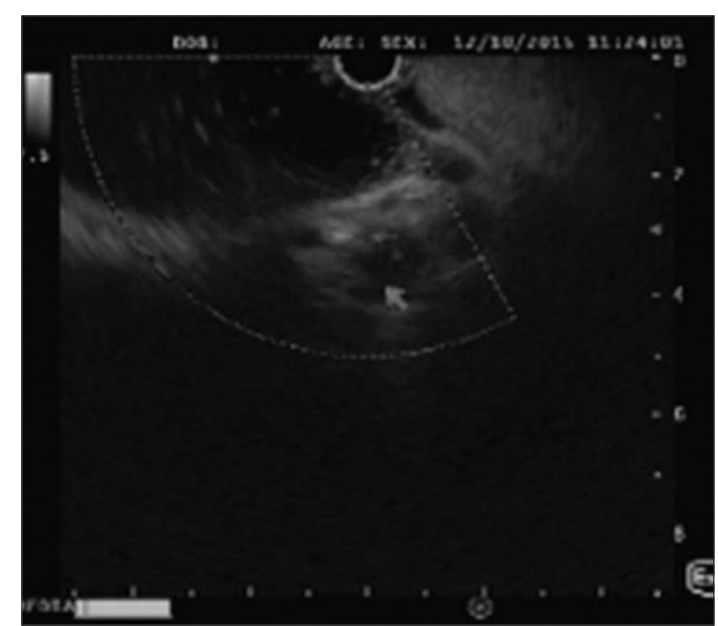

Figure 1: Gallbladder sludge and small calculi

findings were considered suggestive of pancreas divisum if the course of the pancreatic duct could not be followed from the ampulla of Vater through the ventral part to the dorsal pancreas or if the duct could not be visualized within the ventral pancreas. Anomalous pancreaticobiliary junction (APBJ) was defined as abnormally long $(>15 \mathrm{~mm})$ common pancreaticobiliary channel. Stones $<3 \mathrm{~mm}$ in diameter were labeled as microlithiasis as shown in Figure 2.

\section{Results}

We studied 192 patients with acute idiopathic pancreatitis. The mean age of patients was $34.6 \pm 12$ years and male:female ratio was 2.1:1. Of these, 135 patients had gallbladder intact (Group A) and 57 patients had undergone cholecystectomy (Group B). One hundred and two patients had recurrent idiopathic pancreatitis, and ninety patients had only one episode. The mean duration after the last episode of AP when patients were enrolled in the present study was $9.6 \pm 2.2$ weeks.

In Group A (patients with intact gall bladder), EUS identified a possible cause in $79(58.5 \%)$ patients; microlithiasis $(n=48)$, CP $(n=23)$, common bile duct (CBD) with gallbladder stone $(n=3)$, pancreatic divisum $(n=2)$, pancreatic tumor ( $n=2$, branch duct IPMN and pancreatic carcinoma), and anomalous pancreaticobiliary junction $(n=1)$. In Group B, EUS yielded diagnosis in 28 (49.1\%) patients; CP $(n=22)$, ascariasis $(n=3)$, CBD stone $(n=2)$, and pancreatic divisum $(n=1)$. Overall EUS helped in achieving etiological diagnosis in 107 (55.7\%) of patients with IAP. Overall, $58.5 \%$ of patients with gallbladder intact and $47.5 \%$ of postcholecystectomy patients had a positive finding in EUS; comparison of these two groups is shown in Table 1. Microlithiasis was the most common diagnosis achieved (25\%), followed by CP (23.4\%).

Patients who had a diagnosis of pancreas divisum on EUS underwent MRCP, and the findings were confirmed. Of the 85 patients who did not have any diagnosis after EUS, all 


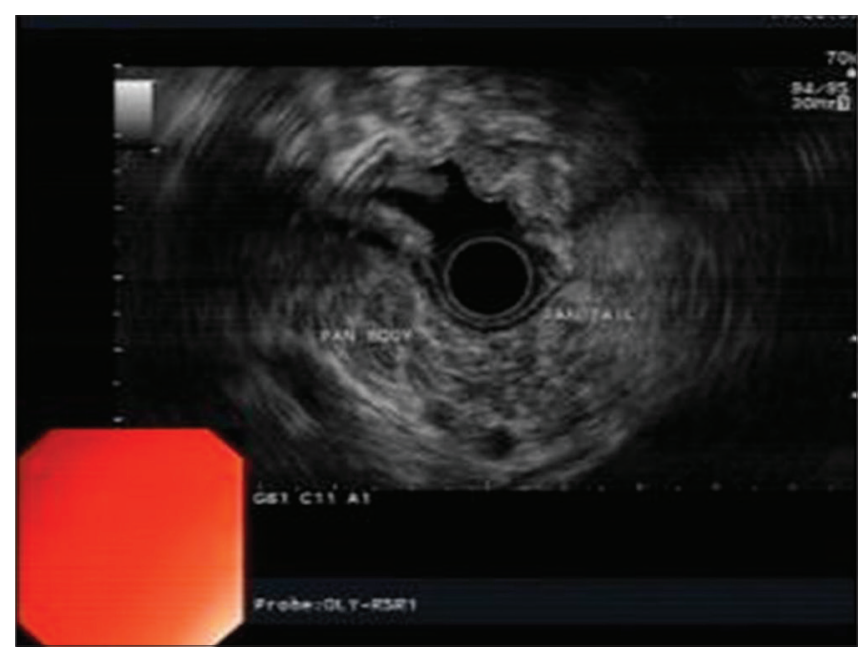

Figure 2: Representative image of early chronic pancreatitis

of them underwent MRCP; it identified APBJ in one and pancreas divisum in two patients. On follow-up, all patients underwent repeat EUS at 3 months, 6 months, and 1 year. Of the 45 patients with EUS diagnosis of $\mathrm{CP}, 32$ had definite criteria for $\mathrm{CP}$ and 13 had probable $\mathrm{CP}$ (in the follow-up, 2 patients developed features of definite $\mathrm{CP}$ at 6 months and another 4 developed features of $\mathrm{CP}$ at 12 months on repeat EUS). Comparison of patients where EUS identified etiology of AP to the patients where EUS was not able to make a diagnosis is shown in Table 2; there was no difference in these groups regarding age, sex, number of AP episodes (single vs. multiple), and history of cholecystectomy.

\section{Discussion}

In this study of 192 patients with IAP, EUS identified an etiology in $55.7 \%$ of patients. The most common etiology identified in this group was gallbladder sludge/microlithiasis and $\mathrm{CP}$, respectively.

Several studies have shown the utility of EUS to diagnose etiology in cases of IAP. A biliary pathology including cholelithiasis, biliary sludge, or CBD stones are the most EUS findings in various studies; it represented $25 \%$ of EUS findings observed in 192 patients in our series. A small series of 40 patients by Rana et al ${ }^{[18]}$ showed that occult biliary pathology was the predominant cause of IAP and half of the cases without identified etiology already had an underlying $\mathrm{CP}$, while another series of 51 patients by Govil et al. ${ }^{[19]}$ revealed that $\mathrm{CP}$ and biliary lithiasis were the common causes of IAP. Endoscopic ultrasonography allows us to visualize microlithiasis and small amount of biliary sludge that is not visible with other imaging techniques including MRCP. The elimination of biliary sludge results in a decrease in the recurrence of new episodes of pancreatitis. ${ }^{[10]}$ The current clinical practice in these cases is to consider biliary sludge and microlithiasis as etiological factors and recommend cholecystectomy in those patients with an acceptable surgical risk. ERCP offers a therapeutic
Table 1: Comparison between two groups of patients with gallbladder in situ and gallbladder removed and the endoscopic ultrasound diagnosis

\begin{tabular}{lccc}
\hline Parameter & $\begin{array}{c}\text { Group A (with } \\
\text { GB in situ), } \boldsymbol{n}(\%)\end{array}$ & $\begin{array}{c}\text { Group B (GB } \\
\text { surgery } \\
\text { earlier), } \boldsymbol{n}(\%)\end{array}$ & $\boldsymbol{P}$ \\
\hline Number of patients & 135 & 57 & \\
Recurrent AP & $61(45.1)$ & $29(50.9)$ & 0.62 \\
EUS able to make & $79(58.5)$ & $28(49.1)$ & 0.62 \\
diagnosis & & & \\
Microlithiasis & $48(35.5)$ & 0 & $<0.01$ \\
Chronic pancreatitis & $23(17.0)$ & $22(38.6)$ & $<0.01$ \\
CBD stones & $3(2.2)$ & $2(3.5)$ & 0.30 \\
Pancreas divisum & $2(1.49)$ & $1(1.75)$ & 0.44 \\
Pancreatic tumor & $2(1.49)$ & 0 & 0.18 \\
Abnormal PB junction & $1(0.7)$ & 0 & 0.26 \\
Ascariasis & 0 & $3(5.3)$ & 0.02 \\
\hline
\end{tabular}

EUS=Endoscopic ultrasound, $\mathrm{PB}=\mathrm{Pancreaticobiliary,} \mathrm{CBD}=\mathrm{Common}$ bile duct, $\mathrm{AP}=$ Acute pancreatitis, $\mathrm{GB}=$ Gallbladder

\begin{tabular}{|c|c|c|c|}
\hline Parameter & $\begin{array}{c}\text { Etiological } \\
\text { diagnosis with } \\
\text { EUS }(n=107)\end{array}$ & $\begin{array}{c}\text { No etiological } \\
\text { diagnosis }(n=87)\end{array}$ & $P$ \\
\hline \multicolumn{4}{|l|}{ Age } \\
\hline$>65$ years $(51)$ & $29(56.9)$ & $22(43.1)$ & 0.81 \\
\hline$<65$ years $(141)$ & $79(56.0)$ & $62(44)$ & \\
\hline Male sex & $74(56.5)$ & $57(43.5)$ & 0.64 \\
\hline \multicolumn{4}{|c|}{ Number of AP episodes } \\
\hline Single & $55(53.9)$ & $47(46.1)$ & 0.59 \\
\hline Recurrent & $52(57.8)$ & $38(42.2)$ & \\
\hline \multicolumn{4}{|c|}{ History of cholecystectomy } \\
\hline Yes (57) & $28(49.1)$ & $25(50.9)$ & 0.06 \\
\hline No (135) & $79(58.5)$ & $60(41.5)$ & \\
\hline
\end{tabular}

$\mathrm{AP}=$ Acute pancreatitis, EUS=Endoscopic ultrasound

advantage in addition to diagnosis in biliary cases; however, EUS is associated with less risk of complications, and it may provide an alternate diagnosis (e.g., CP, small space occupying lesion in the pancreas). EUS provides a diagnosis in $60 \%-80 \%$ of cases and is associated with fewer complications. ${ }^{[4-9,20]}$ As compared to microscopic bile aspiration, EUS has similar ${ }^{[21]}$ or better results ${ }^{[2]}$ for diagnosis of microlithiasis and may provide an alternate diagnosis in up to $25 \%$ of cases. ${ }^{[22]} \mathrm{In}$ patients who underwent cholecystectomy earlier, biliary causes are uncommon, and EUS may be considered the first-line approach to find cause for IAP. EUS is considered as an accurate imaging modality for diagnosis of $\mathrm{CP}$, it has sensitivity, specificity, positive and negative predictive values of $>85 \%$, and has good correlation with ERCP for moderate or severe cases. ${ }^{[16,23]}$ EUS can diagnose small tumors not picked up by CT, and negative predictive value of EUS is close to $100 \%$ for such cases to exclude a tumor. ${ }^{[24]}$ Our study emphasizes the importance of EUS in patients with IAP irrespective of the number of episodes of AP. EUS is particularly useful in patients with intact gallbladder. Our study did not compare the utility of EUS against MRCP/ERCP. Similar studies including 
larger number of patients with a follow-up to evaluate the sustainability of diagnosis will help us understand the exact role of EUS in idiopathic pancreatitis.

To conclude, we present a large series of idiopathic acute pancreatitis where EUS helped in making a probable diagnosis in $55 \%$ of patients.

\section{Financial support and sponsorship}

Nil.

\section{Conflicts of interest}

There are no conflicts of interest.

\section{References}

1. Vila JJ. Endoscopic ultrasonography and idiopathic acute pancreatitis. World J Gastrointest Endosc 2010;2:107-11.

2. Al-Haddad M, Wallace MB. Diagnostic approach to patients with acute idiopathic and recurrent pancreatitis, what should be done? World J Gastroenterol 2008;14:1007-10.

3. Kapetanos D. Endoscopic management of acute recurrent pancreatitis. Annals of Gastroenterology 2010;23:31-7.

4. Vila JJ, Vicuña M, Irisarri R, de la Higuera BG, Ruiz-Clavijo D, Rodríguez-Gutiérrez C, et al. Diagnostic yield and reliability of endoscopic ultrasonography in patients with idiopathic acute pancreatitis. Scand J Gastroenterol 2010;45:375-81.

5. Frossard JL, Sosa-Valencia L, Amouyal G, Marty O, Hadengue A, Amouyal P. Usefulness of endoscopic ultrasonography in patients with "idiopathic" acute pancreatitis. Am J Med 2000;109:196-200.

6. Tandon M, Topazian M. Endoscopic ultrasound in idiopathic acute pancreatitis. Am J Gastroenterol 2001;96:705-9.

7. Coyle WJ, Pineau BC, Tarnasky PR, Knapple WL, Aabakken L, Hoffman BJ, et al. Evaluation of unexplained acute and acute recurrent pancreatitis using endoscopic retrograde cholangiopancreatography, sphincter of Oddi manometry and endoscopic ultrasound. Endoscopy 2002;34:617-23.

8. Liu CL, Lo CM, Chan JK, Poon RT, Fan ST. EUS for detection of occult cholelithiasis in patients with idiopathic pancreatitis. Gastrointest Endosc 2000;51:28-32.

9. Yusoff IF, Raymond G, Sahai AV. A prospective comparison of the yield of EUS in primary vs. recurrent idiopathic acute pancreatitis. Gastrointest Endosc 2004;60:673-8.

10. Ros E, Navarro S, Bru C, Garcia-Pugés A, Valderrama R. Occult microlithiasis in "idiopathic" acute pancreatitis: Prevention of relapses by cholecystectomy or ursodeoxycholic acid therapy. Gastroenterology
1991;101:1701-9.

11. Neoptolemos JP, Davidson BR, Winder AF, Vallance D. Role of duodenal bile crystal analysis in the investigation of 'idiopathic' pancreatitis. Br J Surg 1988;75:450-3.

12. Gregor JC, Ponich TP, Detsky AS. Should ERCP be routine after an episode of "idiopathic" pancreatitis? A cost-utility analysis. Gastrointest Endosc 1996;44:118-23.

13. Testoni PA, Mariani A, Curioni S, Zanello A, Masci E. MRCP-secretin test-guided management of idiopathic recurrent pancreatitis: Long-term outcomes. Gastrointest Endosc 2008;67:1028-34.

14. Kondo S, Isayama H, Akahane M, Toda N, Sasahira N, Nakai Y, et al. Detection of common bile duct stones: Comparison between endoscopic ultrasonography, magnetic resonance cholangiography, and helical-computed-tomographic cholangiography. Eur J Radiol 2005;54:271-5.

15. Verma D, Kapadia A, Eisen GM, Adler DG. EUS vs. MRCP for detection of choledocholithiasis. Gastrointest Endosc 2006;64:248-54.

16. Irisawa A, Katakura K, Ohira H, Sato A, Bhutani MS, Hernandez LV, et al. Usefulness of endoscopic ultrasound to diagnose the severity of chronic pancreatitis. J Gastroenterol 2007;42 Suppl 17:90-4.

17. Catalano MF, Sahai A, Levy M, Romagnuolo J, Wiersema M, Brugge W, et al. EUS-based criteria for the diagnosis of chronic pancreatitis: The Rosemont classification. Gastrointest Endosc 2009;69:1251-61.

18. Bournet B, Migueres I, Delacroix M, Vigouroux D, Bornet JL, Escourrou J, et al. Early morbidity of endoscopic ultrasound: 13 years' experience at a referral center. Endoscopy 2006;38:349-54.

19. Rana SS, Bhasin DK, Rao C, Singh K. Role of endoscopic ultrasound in idiopathic acute pancreatitis with negative ultrasound, computed tomography, and magnetic resonance cholangiopancreatography. Ann Gastroenterol 2012;25:133-7.

20. Govil A, Agrawal MK, Agrawal D, Udawat H. Role of endoscopic ultrasonography in patients with first episode of idiopathic acute pancreatitis. Indian J Gastroenterol 2014;33:241-8.

21. Dahan P, Andant C, Lévy P, Amouyal P, Amouyal G, Dumont M, et al. Prospective evaluation of endoscopic ultrasonography and microscopic examination of duodenal bile in the diagnosis of cholecystolithiasis in 45 patients with normal conventional ultrasonography. Gut 1996;38:277-81.

22. Vila JJ, Arín A, Borobio E, Arín B, Irisarri R, Jiménez FJ, et al. Prospective double blinded comparison of endosonography versus microscopic bile examination for diagnosing microlithiasis in patients with biliary colic or idiopathic acute pancreatitis. Endoscopy 2007;39 Suppl 1:A281.

23. Sahai AV, Zimmerman M, Aabakken L, Tarnasky PR, Cunningham JT, van Velse A, et al. Prospective assessment of the ability of endoscopic ultrasound to diagnose, exclude, or establish the severity of chronic pancreatitis found by endoscopic retrograde cholangiopancreatography. Gastrointest Endosc 1998;48:18-25.

24. Klapman JB, Chang KJ, Lee JG, Nguyen P. Negative predictive value of endoscopic ultrasound in a large series of patients with a clinical suspicion of pancreatic cancer. Am J Gastroenterol 2005;100:2658-61. 